\title{
An investigation into the enhancement of fingermarks in blood on fruit and vegetables
}

\author{
Laura Rae, Dennis Gentles, Kevin J. Farrugia*
}

School of Contemporary Sciences, Division of Environment and Forensic Sciences, University of Abertay, Dundee, DD1 1HG, UK

\footnotetext{
* Corresponding Author:
}

School of Contemporary Sciences

Division of Environment and Forensic Sciences

University of Abertay

Dundee DD1 1HG

United Kingdom

tel: $+44(0) 1382308689$

fax: +44 (0) 1382308663

kevin.farrugia@abertay.ac.uk 


\begin{abstract}
A number of studies have reported the successful enhancement of latent fingermarks on fruit and vegetables. A study was set up to identify the most effective technique for the enhancement of fingermarks in blood on various fruit and vegetables. The enhancement techniques targeted different components in blood and consisted of protein stains (e.g. acid black 1), peroxidase reagents (e.g. leuco crystal violet) and amino acid stains (e.g. ninhydrin). Different variables such as the ageing periods of the marks and a diminishing series were employed to assess the suitability and sensitivity of the enhancement techniques.

Overall, the use of different protein stains appeared to be the most effective techniques for the enhancement of fingermarks in blood on fruit and vegetables. In addition, the aubergine and cucumber skins appeared to be the most responsive surface to the different chemical techniques during enhancement. On the contrary, little or no enhancement was achieved for fingermarks in blood on the nectarine fruit.
\end{abstract}

Keywords: fingermarks, blood enhancement, fruit and vegetables, protein stains, peroxidase reagents, amino acid staining 


\section{INTRODUCTION}

Fruit and vegetables are common food items in many households. Singh and Sodhi [1] investigated the development of latent fingermarks on a range of fruit and vegetables including apples, bananas, onions, and potatoes. The best enhancement results were obtained by brushing with black powder whereas iodine fuming proved to be the least suitable technique. A further study by Trapecar and Vinkovic [2] compared two fingermark powders and cyanoacrylate fuming where Swedish Black powder produced the best results with the clearest ridge detail irrespective of the different surface types and cyanoacrylate fuming provided little, if any, enhancement. In both studies, black powder and apples appeared to be the most responsive technique and surface for enhancement and recovery of latent fingermarks [1, 2]. A recent study [3] has shown that black magnetic powder might be a more suitable brushing technique for the enhancement of latent fingermarks on fruit and vegetables. Nonetheless, a modified formulation of black powder suspensions provided ridge detail enhancement that was superior to that of black magnetic powder. In addition, the enhancement with powder suspensions appeared to provide better results with ageing of the fingermark [3].

The aim of this study was to assess and investigate the potential enhancement of fingermarks in blood on various fruit and vegetables by means of a diminishing series and various ageing periods. 


\section{Materials and Methods}

\section{Preparation of fruit and vegetables}

Five fruits and vegetables (aubergines, bananas, cucumbers, nectarines and oranges) were selected for a variety of surface type and colour. In some parts of the world aubergine may be known as eggplant. All food items were purchased locally the day they were required, cleaned with distilled water and dried with chemical free paper towels. Only one person donated their fingermarks who was instructed to dab their right index finger in sterilised horse blood before pressing twice onto clean chemical free paper towel to remove the excess blood. The use of a diminishing series (or depletion series) is routinely used in the determination of the relative sensitivity of a technique for research into the effectiveness of enhancement techniques [4]. After loading the finger/footwear with blood, a series of marks is made without reloading where less blood is transferred down the diminishing series. This is only true if the pressure of deposition is kept constant $[5,6]$. The deposition pressure was not controlled in the study; however, the described methodology attempted to limit the variability of this pressure. A diminishing series of 8 fingermarks in blood, ranging from visible to barely visible to latent, were then planted in a row along the straight fruits and vegetables (bananas, cucumbers and aubergines) and around the centre of the round fruits (oranges and nectarines). The pressure of deposition was not controlled; however, the donor was instructed to attempt to keep a constant force. Once the fingermarks were planted, the fruit and vegetables were stored in the laboratory at room temperature for the ageing periods of 1 day, 3 days, 7 days, 14 days and 21 days. Longer ageing periods were considered; however, the decomposition of the food item, rather than the enhancemet technique, would have affected the quality of the fingermark.

\section{Controls}

A positive control of the chemicals was done by planting a depletion series in blood on paper (porous) and tiles (non-porous) followed by chemical treatment and observation of any enhancement achieved. The negative control was done by treating the food items with chemicals without any blood present to ensure that chemicals did not react with anything orginating from the fruit or vegetables. 


\section{Photography and Fluorescence}

Each diminishing series in blood was photographed before and after enhancement using a Nikon D5000 digital SLR camera with a 55mm lens. The photographs were not manipulated by the use of specialised software. Fluorescence observations were performed using a Mason Vectron Quaser 2000/30 connected to an Integrated Rapid Imaging System (IRIS).

\section{Enhancement Techniques}

\section{Protein stains [7]}

$1 \mathrm{~g}$ of the required protein stain [BVDA: acid black 1 (AB1), acid violet 17 (AV17), acid yellow 7 (AY7)] was thoroughly dissolved in distilled water $(700 \mathrm{~mL})$, ethanol (Fisher, 250 $\mathrm{mL}$, analytical grade) and acetic acid (Fisher, $50 \mathrm{~mL}$, analytical grade). The fixative solution was prepared by dissolving 5-sulfosalicylic acid dihydrate (Acros, 23g) in distilled water $(1000 \mathrm{~mL})$. The rinsing solution consisted of distilled water $(700 \mathrm{~mL})$, ethanol (Fisher, 250 $\mathrm{mL}$, analytical grade) and acetic acid (Fisher, $50 \mathrm{~mL}$, analytical grade). The item to be enhanced was immersed in the fixing agent for at least five minutes followed by immersion in the appropriate protein stain for a further 10 minutes. Finally the item was immersed in the rinsing solution to wash off the excess stain. The items enhanced with AY7 were observed under the Quaser using a blue excitation source (band pass filter 385-509nm at 1\% cut-on and cut-off points respectively) and viewed with a long pass $510 \mathrm{~nm}$ filter (1\% cut-on point).

\section{Ninhydrin [8]}

Ninhydrin (6g, Sigma) was completely dissolved in absolute ethanol (50 mL, Fisher, analytical grade) using a magnetic stirrer. Petroleum ether $(950 \mathrm{~mL}$, Fisher, analytical grade) was then added with further stirring. The ninhydrin solution was poured into a shallow glass dish and the item to be treated was immersed in the solution for a few seconds. The samples were then allowed to air dry before subjected to heat and humidity using a conventional steam iron for at least 20 minutes. The iron, with a steam temperature of about $90^{\circ} \mathrm{C}$, was held above the surface of the article to be examined with the necessary precautions to avoid scorching and excess background development. 


\section{$\underline{\mathrm{DFO}[8]}$}

DFO (0.5g, Sirchie) was completely dissolved in methanol $(100 \mathrm{~mL}$, Fisher, analytical grade), ethyl acetate $(100 \mathrm{~mL}$, Fisher, analytical grade) and acetic acid (20 mL, Fisher, analytical grade) using a magnetic stirrer. Petroleum ether $(780 \mathrm{~mL}$, Fisher, analytical grade) was then added with further stirring. Items to be treated with DFO were immersed in the solution for a few seconds, air dried and subjected to heat using an iron (without water) for at least 30 minutes. The iron was held in close proximity to the surface of the article to be examined with the necessary precautions to avoid scorching and excess background development.

The formulations for ninhydrin and DFO in this study used petroleum ether rather than HFE solvents, as recommended by Ramotowski if flammability is not a major concern [8]. The standard conditions for ninhydrin $\left(80^{\circ} \mathrm{C}\right.$ and $65 \%$ relative humidity) and $\mathrm{DFO}\left(100^{\circ} \mathrm{C}\right)$ were not used to avoid damaging/destroying the fruit or vegetable. Observations for enhanced fingermarks were made immediately and after 24 hours.

\section{$\underline{\text { Leucomalachite Green (LMG) [8] }}$}

5-sulfosalicyclic acid dihydrate (Acros, 2.2g) was thoroughly dissolved in distilled water $(100 \mathrm{~mL})$ followed by the addition of leucomalachite green $(\mathrm{BDH}, 0.16 \mathrm{~g})$. To this was added $30 \%$ hydrogen peroxide (Fisher, $10 \mathrm{~mL}$ ) with further stirring. The solution was prepared just prior to use and the reagent was applied by spraying with Ecospray ${ }^{\circledR}$.

\section{$\underline{\text { Leuco crystal violet (LCV) [9] }}$}

5-sulphosalicyclic acid dihydrate (Acros, 10g) was thoroughly dissolved in 3\% hydrogen peroxide (Fisher, $500 \mathrm{~mL}$ ). Sodium acetate (Sigma, 3.7g) was added to the mixture followed by leuco crystal violet (Acros, $1 \mathrm{~g}$ ) and stirred to dissolve using a magnetic stirrer. The items to be treated were then sprayed with Ecospray ${ }^{\circledR}$ and observed visually as well as under the IRIS using a green/yellow excitation source (band pass filter 503-591nm at $1 \%$ cut-on and cut-off points respectively) and viewed with a long pass $593 \mathrm{~nm}$ filter (1\% cut-on point).

\section{$\underline{\text { Luminol }}$}

The commercial product Bluestar ${ }^{\circledR}$ Forensic Magnum was used by following the manufacturer's instructions. It was prepared by dissolving the three tablets in $125 \mathrm{~mL}$ of the liquid supplied and the reagent was sprayed using an Ecospray ${ }^{\circledR}$. 
The use of Ecospray ${ }^{\circledR}$ for the delivery of LCV, LMG and Bluestar ${ }^{\circledR}$ Forensic Magnum provided a fine mist delivery which is less likely to cause diffusion of marks.

\section{Grading of fingermarks}

All the fingermarks, before and after enhancement, were graded using the grading scheme recommended by the UK Centre for Applied Science and Technology (CAST) in table 1 [4]. This grading allowed fingermarks to be enhanced positively (the grade after enhancement was higher than the grade before enhancement), negatively (the grade after enhancement was lower than the grade before enhancement) or enhanced to show no change (the grade after enhancement was the same as it was before enhancement).

Table 1: Grading scheme for assessment of developed fingermarks

\begin{tabular}{|c|c|}
\hline Grade & Level of Detail \\
\hline 0 & No evidence of mark \\
\hline 1 & Some evidence of contact but no ridge detail present \\
\hline 2 & Less than $1 / 3$ of mark showing clear ridge detail \\
\hline 3 & Between $1 / 3$ and $2 / 3$ of mark showing clear ridge detail \\
\hline 4 & Over $2 / 3$ of mark showing clear ridge detail \\
\hline
\end{tabular}




\section{Results and discussion}

\section{Controls}

The positive controls demonstrated that all enhancement techniques were working giving a colour or a fluorescent/chemilluminscent reaction; however, DFO provided little, if any, fluorescence for a reaction with blood. DFO was tested further on latent fingermarks and the fluorescence observed was much stronger than for fingermarks in blood. No observations were made, colour or fluorescent, for negative controls.

\section{Protein Stains}

The aubergine, cucumber and banana yielded the highest number of grade 3 and 4 fingermarks after enhancement with the protein stains acid black 1 (AB1), acid violet 17 (AV17) and acid yellow 7 (AY7). Individually, AB1 produced the best enhancement results on fingermarks in blood on cucumber after an ageing period of 14 and 21 days whereas AV17 and AY7 demonstrated superior enhancement results for fingermarks in blood on banana and aubergine respectively after an ageing period of 1 day. Limited background fluorescence from the substrates did not appear to improve or hinder the enhancement observed for marks treated with AY7. The nectarine and orange surfaces only provided limited enhancement of fingermarks in blood across all ageing periods and in some cases the original mark was completely obscured or obliterated. Figures 1-3 illustrate examples of protein stain enhancement observed for fingermarks in blood.

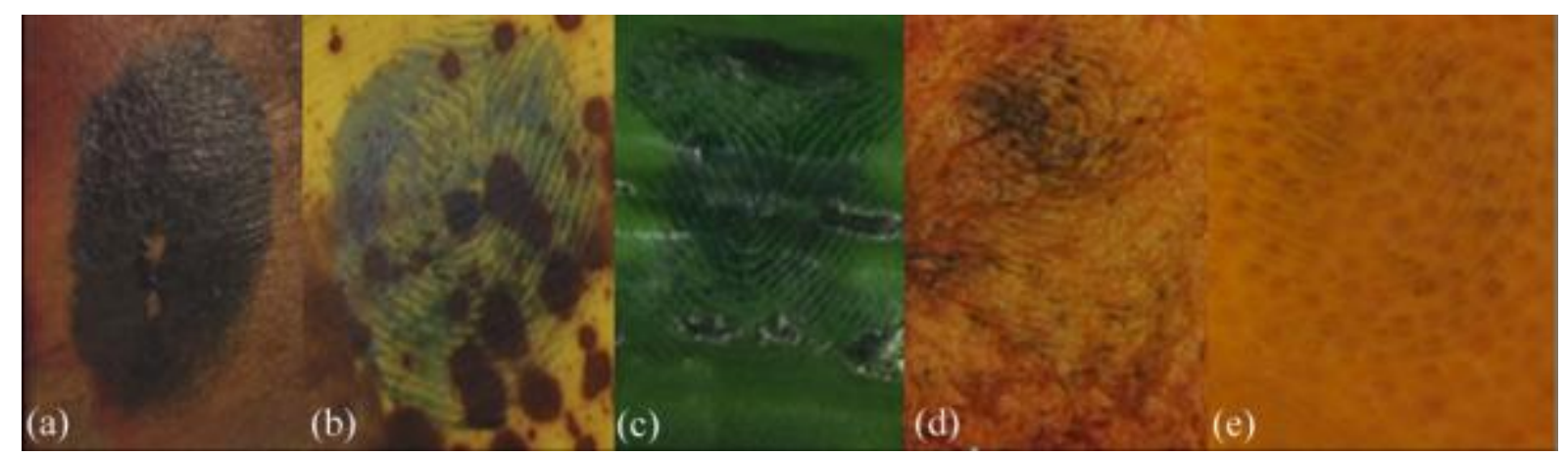

Figure 1 - Enhancement of the $6^{\text {th }}$ fingermark in the diminishing series with Acid Black 1 after an ageing period of 14 days: (a) aubergine; (b) banana; (c) cucumber; (d) nectarine; (e) orange 


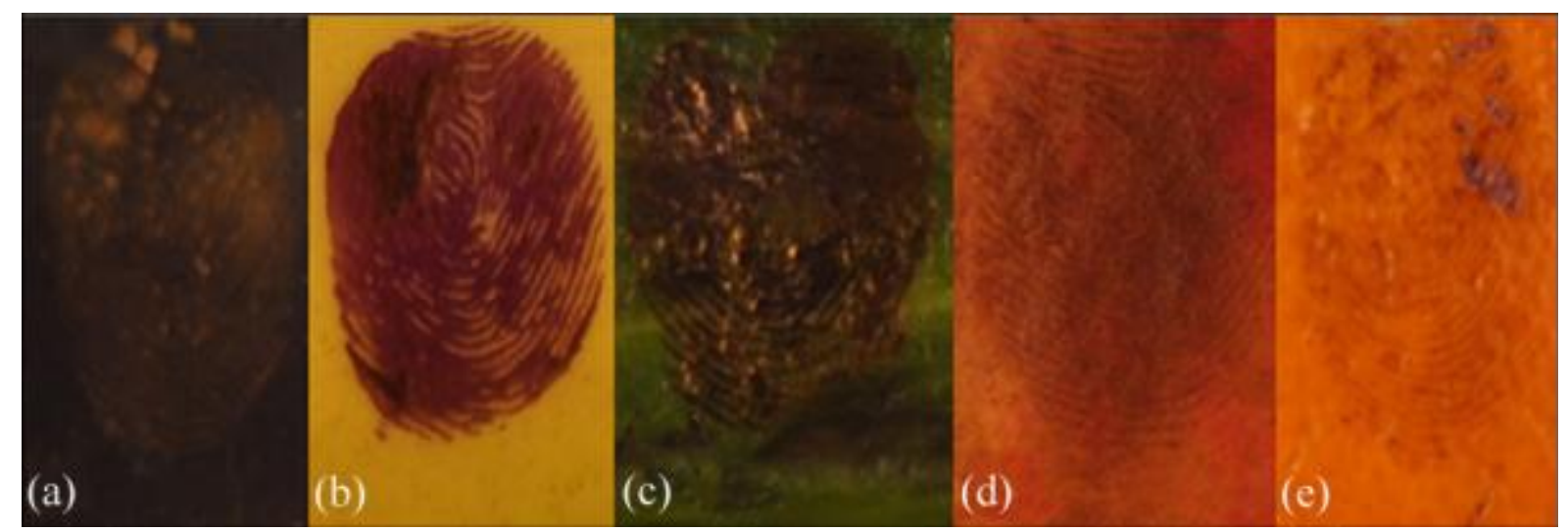

Figure 2 - Enhancement of the $6^{\text {th }}$ fingermark in the diminishing series with Acid Violet 17 after an ageing period of 1 day: (a) aubergine; (b) banana; (c) cucumber; (d) nectarine; (e) orange

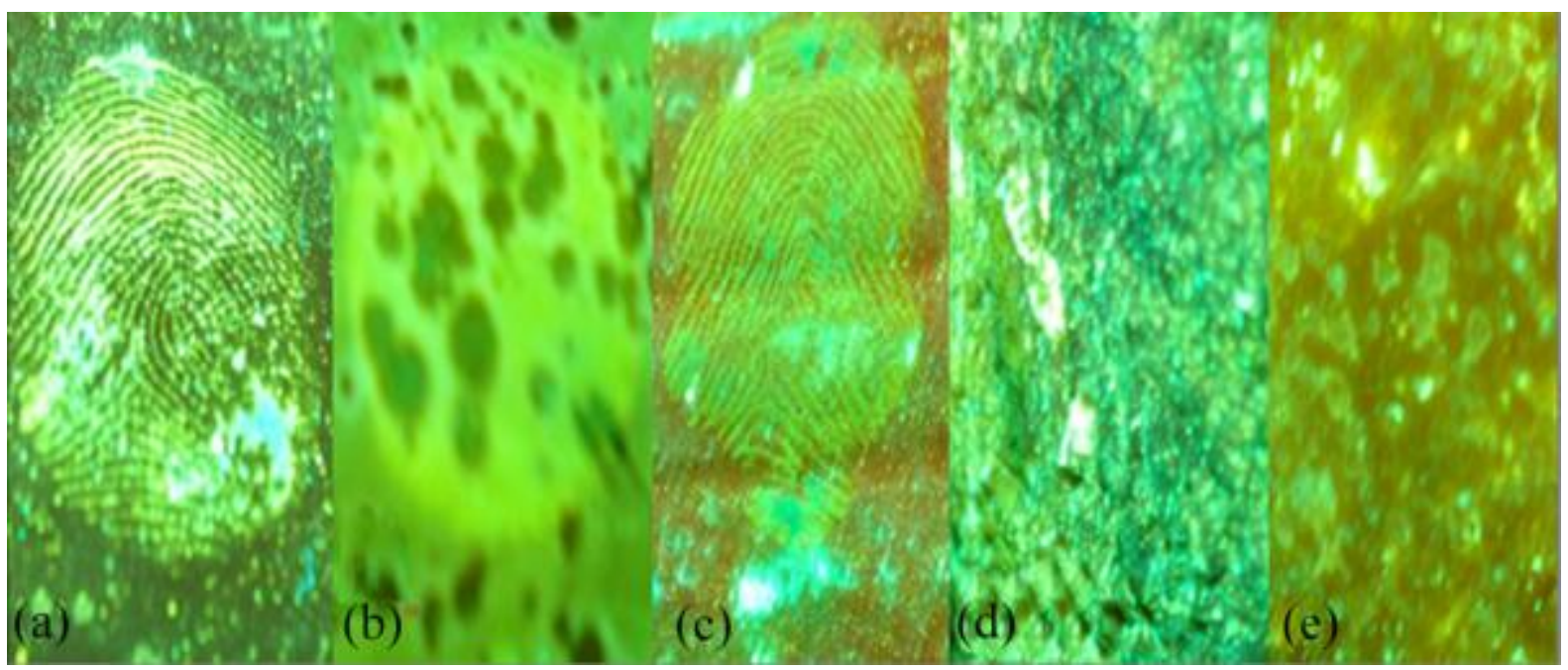

Figure 3 - Enhancement of the $6^{\text {th }}$ fingermark in the diminishing series with Acid Yellow 7 after an ageing period of 1 day (viewed using a 385-509nm excitation filter and a 510nm viewing filter): (a) aubergine; (b) banana; (c) cucumber; (d) nectarine; (e) orange

\section{Peroxidase Reagents}

Leuco crystal violet (LCV) treatment appeared to yield the highest number of grade 3 and 4 fingermarks on cucumber and aubergine after an ageing period of 21 days. In some instances, the use of fluorescence allowed the visualisation of the fingermark in blood; however, on other occasions the use of fluorescence hindered the visualisation of the mark (figure 4). The use of leuco malachite green (LMG) did not provide any suitable enhancement results for any of the surfaces and ageing periods tested. Luminol enhancement of fingermarks in blood only yielded limited enhancement (grade 1 and 2) as the fine detail of the fingermark was not fully recovered due to diffusion of the original mark. The use of luminol as an enhancement 
technique for blood works well for footwear marks in blood; however, it might not be as useful for the recovery of fingermarks in blood [10-11]. Similar to protein stains, the peroxidase reagents provided poor enhancement on the nectarine and orange surfaces although luminol appeared to provide superior results on nectarine when compared to other fruit and vegetable surfaces (figure 5).

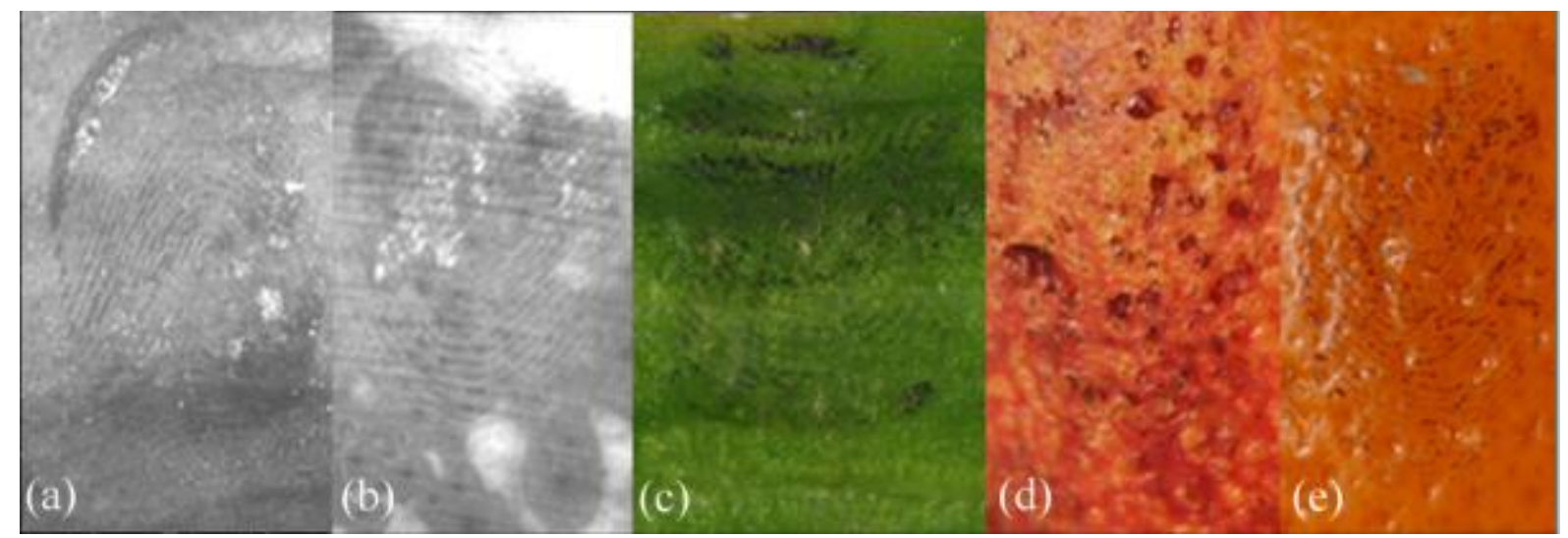

Figure 4 - Enhancement of the $5^{\text {th }}$ fingermark in the diminishing series with LCV after an ageing period of 21 days: (a) aubergine; (b) banana (viewed using a 503-591nm excitation filter and a $593 \mathrm{~nm}$ viewing filter) and (c) cucumber; (d) nectarine; (e) orange (viewed under white light)

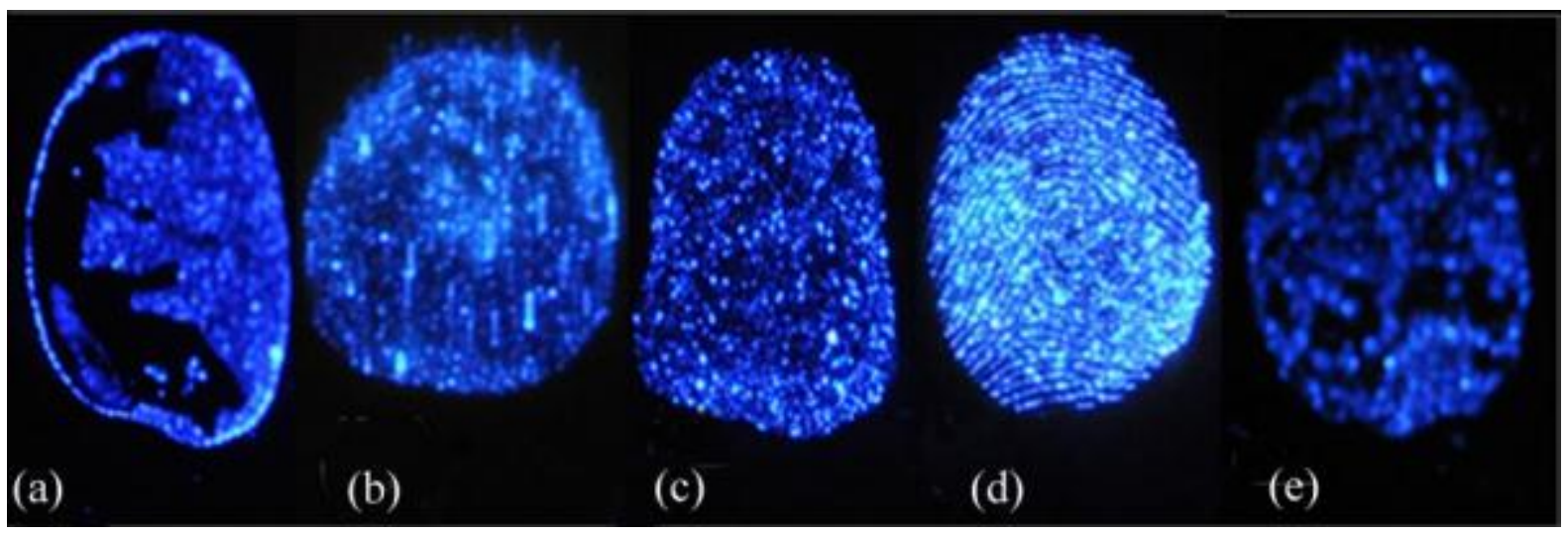

Figure 5 - Enhancement of the $5^{\text {th }}$ fingermark in the diminishing series with Bluestar Forensic Magnum Luminol after an ageing period of 21 days: (a) aubergine; (b) banana; (c) cucumber; (d) nectarine; (e) orange 


\section{Amino Acid Stains}

Ninhydrin and DFO provided litte, if any, enhancement for the visualisation of fignermarks in blood on the surfaces tested in the study. A possible explanation is the modified treament employed in this study so as to prevent the destruction of the surface. Furthermore, ninhydrin and DFO treatments are recommended for porous surfaces and since the fruit/vegetable surfaces in this study demonstrated non-porous properties, the amino acids in blood may have been washed away during chemical treatment. Figure 6 demonstrates an example of fingermarks in blood enhanced with the modified ninhydrin method. There was no difference in the observations made immediately or after 24 hours.

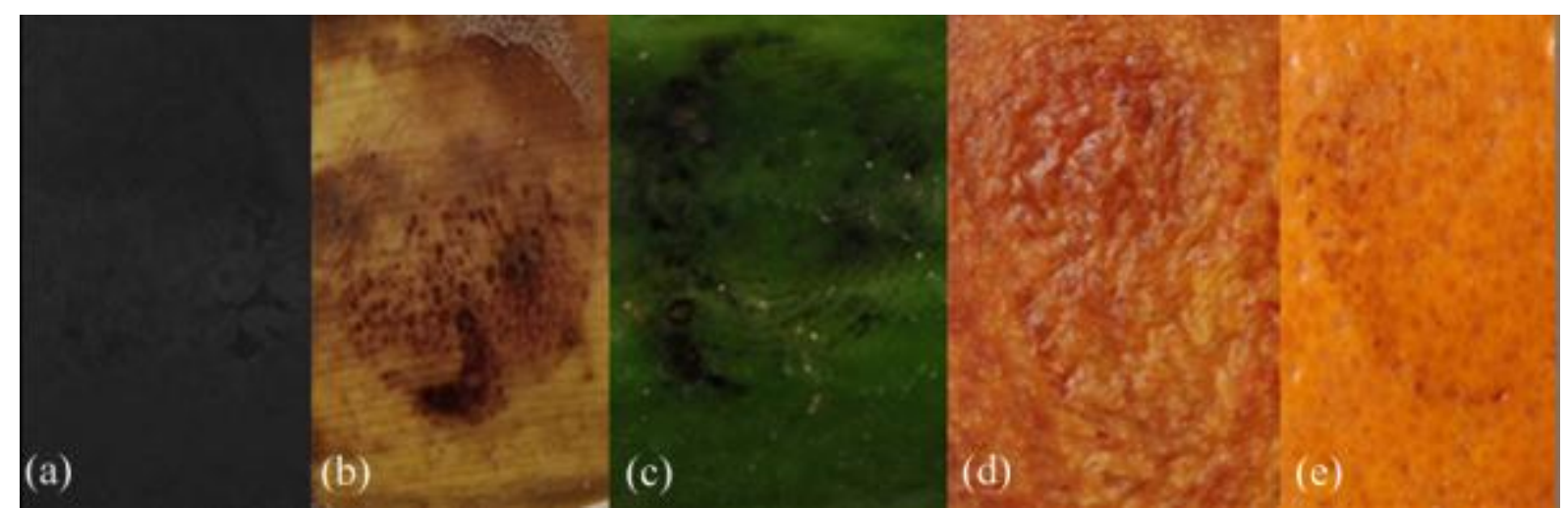

Figure 6 - Enhancement of the $5^{\text {th }}$ fingermark in the diminishing series with a modified ninhydrin treatment after an ageing period of 3 days: (a) aubergine; (b) banana; (c) cucumber; (d) nectarine; (e) orange

\section{Evaluation of enhancement techniques}

The chemical techniques for the enhancement of fingermarks in blood were assessed by calculating the percentage of positive enhancements for each technique across all the fruits/ vegetables and time periods. A fingermark was included as a positive enhancement if there was an improvement in the quality of the mark after enhancement (a higher grading than before enhancement). Figure 7 demonstrates that the use of the protein stains AB1 and AV17 provided the most suitable enhancement in this study. Although AY7 provided a lower percentage of positive enhancements, it yielded superior results than AB1 and AV17 on the dark aubergine surface due to the advantage of fluorescence.

LCV yielded a similar number of positive enhancements when compared to AB1 and AV17; however, there are some safety concerns surrounding the use of LCV and LMG. The use of 
DFO did not provide any positive enhancements and in most cases there was a deterioration of the original mark. Previous studies have suggested that the use of DFO for the enhancement of marks made in blood may be hindered by the surface of the substrate and associated fluorescence quenching where the enhancement of footwear impressions in blood on fabric with DFO was found to be ineffective [12]. This appears to be contrary to other studies where DFO was found to be extremely sensitive for the development of fingermarks in blood on porous surfaces and also produced highly fluorescent marks with the lightest marks [10]. Figure 8 (LMG and DFO have been omitted from the graph as no/limited enhancement was achieved) reveals that AB1 and AV17 produced the best overall enhancement results.

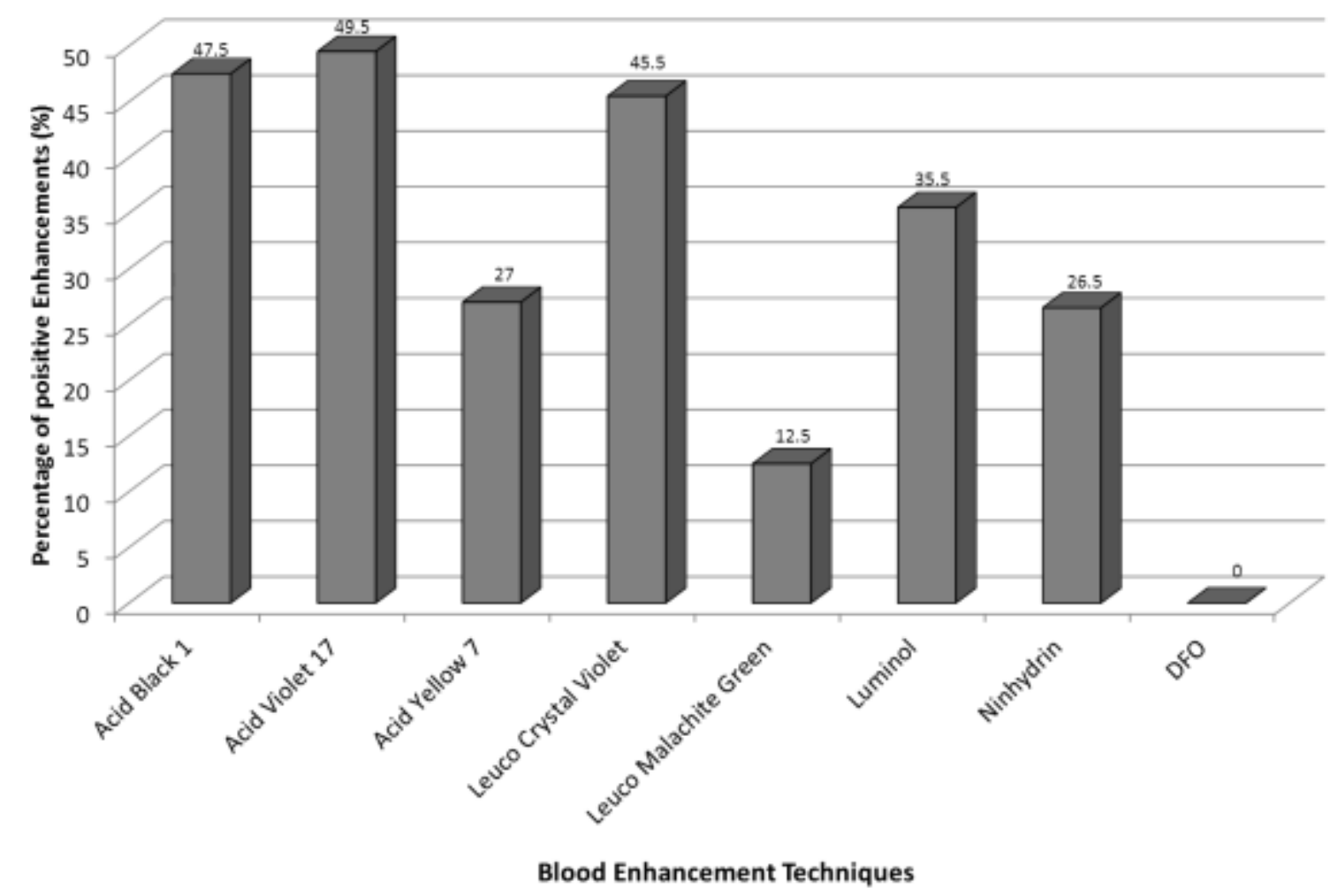

Figure 7 - Positive grading of fingermarks by blood enhancement technique for all surfaces and ageing periods

\section{Ageing of fingermarks in blood}

Figure 9 demonstrates no correlation between the ageing of the fingermark in blood on the food items and the grading quality of the fingermarks after enhancement, although the 0 grading for 21 days appeared to be higher than the other ageing periods. Analysis of the fingermark gradings for nectarine revealed a clear correlation between the ageing period and fingermark quality where the latter decreased with increased ageing. This might be explained 
by the decomposition of nectarine as it appeared that the fruit (main body between the skin and the inner stone) shrank during decomposition causing the nectarine skin to shrivel up and to obliterate any ridge detail that might have been present. In contrast, the orange surface did not demonstrate any noticeable decomposition throughout the maximum ageing period of 21 days; however, the enhancement observed was inferior to that of other food items possibly due to the surface roughness of the orange. A wax layer is generally applied to citrus fruits for aesthetic reasons and to retard decomposition which may interfere with or hinder the enhancement reaction. 


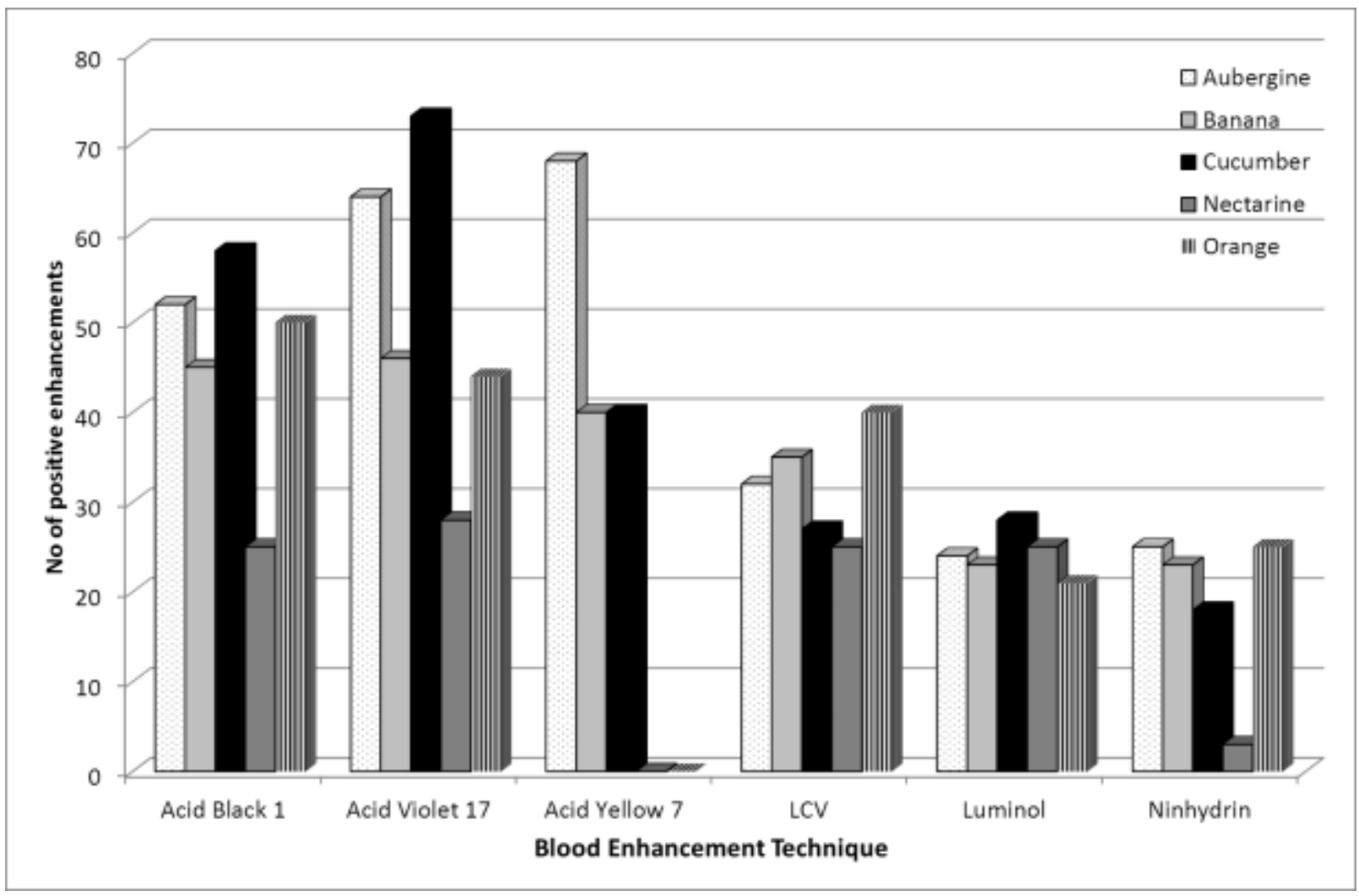

Figure 8 - Comparison of enhancement techniques across different food items for all ageing periods

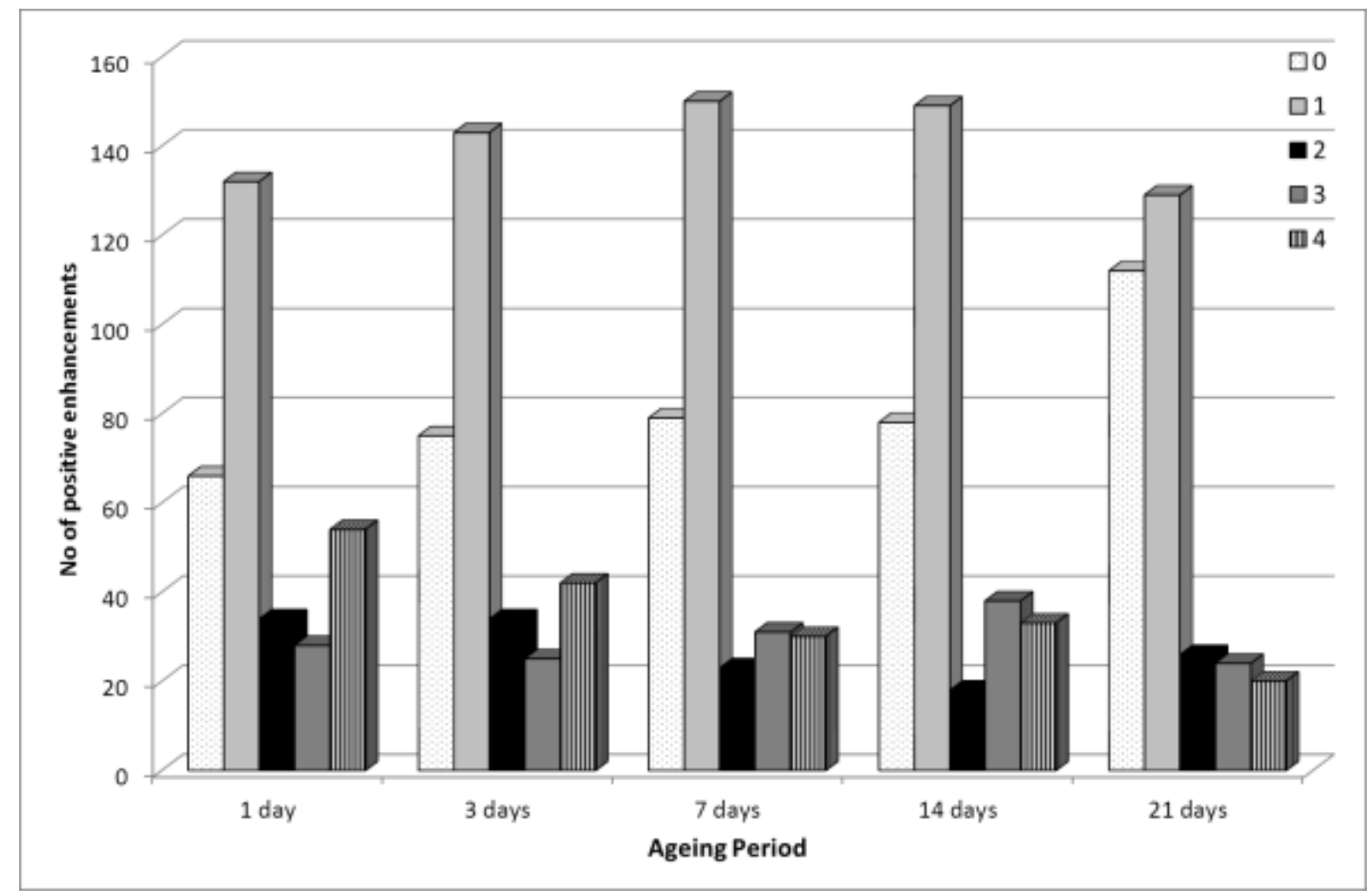

Figure 9 - Comparison of fingermark grading across the different ageing periods for all fruit/vegetables and enhancement techniques 


\section{Diminishing Series}

The first three fingermarks (FM) in the diminishing series have a very high number of 0 and 1 gradings as demonstrated in figure 10. Higher gradings of 3 and 4 were obtained further down the diminishing series as less blood was present suggesting that the first marks in the diminishing series might have been over-loaded and although enhancement might have been successful, the recovery of ridge detail was not.

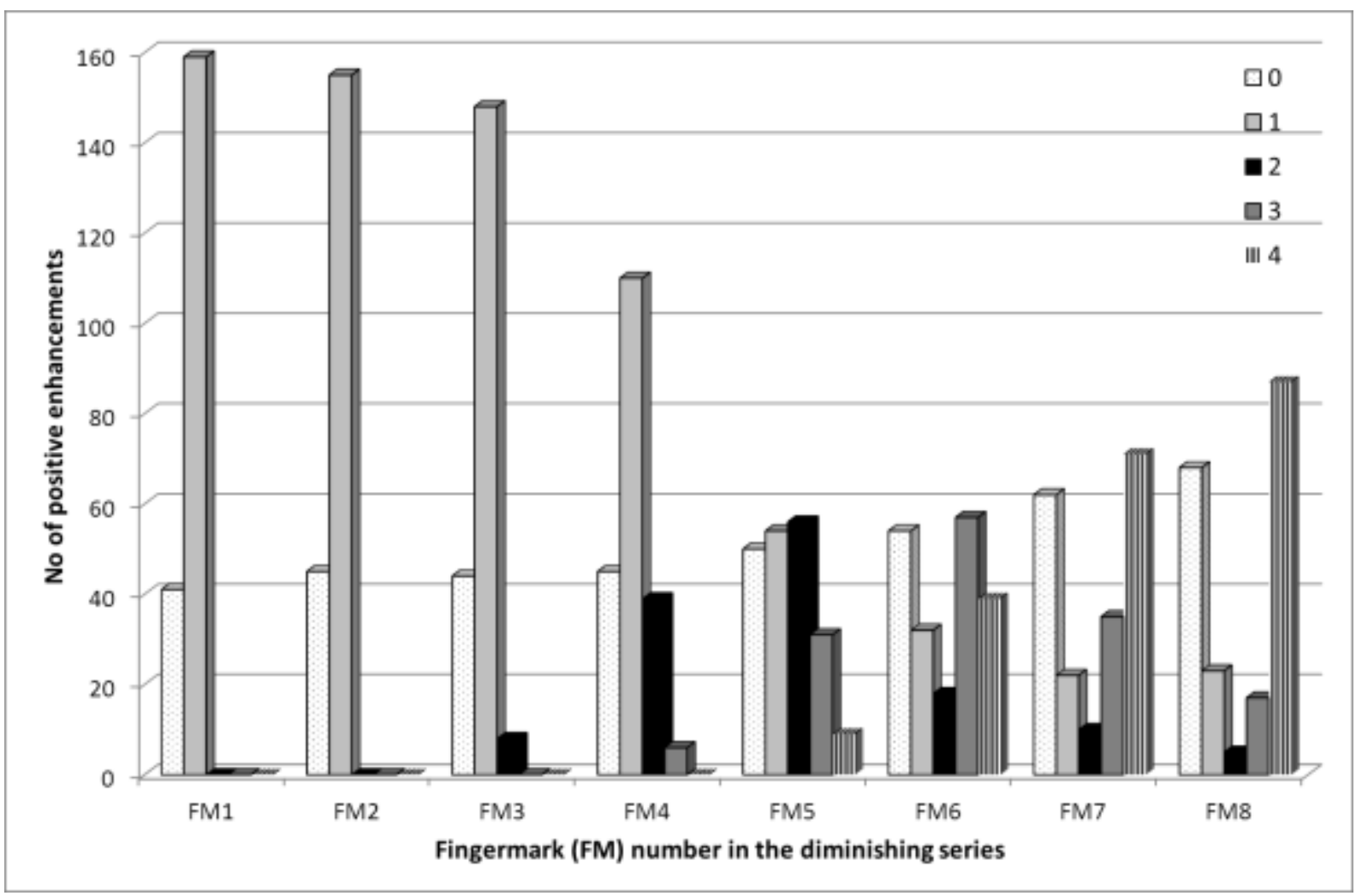

Figure 10 - Comparison of fingermark grading across the diminishing series 


\section{Conclusion}

This preliminary study for the enhancement of fingermarks in blood on fruit and vegetables revealed that the recovery of such marks may be possible. The aubergine, cucumber and banana surfaces appeared to respond better to enhancement techniques used in this study when compared with the nectarine and orange surfaces. The use of protein stains provided the best recovery of ridge detail. Furthermore, proteins stains are cheap, readily available, safe and easy to use. Although the use of peroxidase reagents such as LCV and luminol (by spraying) may provide similar enhancement to protein stains (by immersion), safety concerns related to their carcinogenic effects have stopped widespread use of such chemicals. The use of ninhydrin may also provide added advantages as it may detect both latent and blood fingermarks; however, its enhancement properties for blood appeared to be inferior to that of the protein stains. The use of DFO did not provide any suitable enhancement and there appears to be conflicting research articles on DFO as a reagent for the suitable enhancement of marks in blood. It must be stressed that ninhydrin and DFO treatments are recommended for porous items and surfaces tested in this study were non-porous. Furthermore, the optimum conditions for ninhydrin $\left(80^{\circ} \mathrm{C}, 65 \%\right.$ relative humidity) and $\mathrm{DFO}\left(100^{\circ} \mathrm{C}\right)$ were not strictly applied to avoid destruction of the surface. It is also probable that the use of 1,2-indanedione would be ineffective due to the aforementioned reasons. Future work will assess the use of other alternative enhancement techniques (e.g. powder suspensions and quantum dots) for the recovery of fingermarks in blood on fruit and vegetables. 


\section{References}

1. G. Singh, G.S. Sodhi, O.P. Jasuja. Detection of Latent Fingermarks on Fruits and Vegetables, Journal of Forensic Identification, 56 (3) (2006) 374-381.

2. M. Trapecar, M.K. Vinkovic. Techniques for fingermark recovery on vegetable and fruit surfaces used in Slovenia - A preliminary study, Science \& Justice, 48 (4) (2008) 192-195.

3. S. Ferguson, L. Nicholson, K.J. Farrugia, D. Bremner, D. Gentles. A preliminary investigation into the acquisition of fingermarks on food, Science and Justice, 53 (1) (2013) 67-72

4. V.G. Sears, S.M. Bleay, H.L. Bandey, V.J. Bowman. A methodology for fingermark research. Science and Justice, 51 (3) (2012) 145-16

5. S. Fieldhouse, Consistency and reproducibility in fingermark deposition, Forensic Science International, 207 (2011) 96-100

6. K.J. Farrugia, P. Riches, H.L. Bandey, N. Nic Daéid, Controlling the Variable of Pressure in the Production of Test Footwear Impressions, Science and Justice, 52 (3) (2012) 168-176

7. Bowman, V., Ed. Manual of Fingerprint Development Techniques, 2nd ed. 2005, Home Office Scientific Development Branch: Sandridge, UK.

8. R.S. Ramotowski. Amino Acid Reagents, in: Lee and Gaensslen's Advances in Fingermark Technology, $3^{\text {rd }}$ Edition, R.S. Ramotowski, Ed., CRC Press: Florida, (2012) 17-54

9. Bodziak, W.J., Footwear Impression Evidence: Detection, Recovery and Examination, 2nd ed. 2000, London: CRC Boca Raton.

10. V.G. Sears, C.P.G. Butcher, L.A. Fitzgerald. Enhancement of fingerprints in blood Part 3: reactive techniques, acid yellow 7, and process sequences, Journal of Forensic Identification, 55 (6) (2005) 741-763

11. K.J. Farrugia, K.A. Savage, H.L. Bandey, T. Ciuksza, N. Nic Daéid, Chemical Enhancement of Footwear Impressions in Blood on Fabric - Part 2: Peroxidase reagents, Science \& Justice, 2011, 51 (3) 110-121

12. K.J. Farrugia, H.L. Bandey, K.A. Savage, N. Nic Daéid. Chemical Enhancement of Footwear Impressions in Blood on Fabric - Part 3: Amino Acid Staining, Science and Justice, 53 (1) (2013) 8-13 